\title{
A UTIlizaçÃo da GaMificaÇÃo aliada Às TeCNOLOGIas Digitais NO ENSINO DA MATEMÁtica: UM PANORAMA DE PESQUISAS BRASILEIRAS
}

\author{
THE USE OF GAMIFICATION COMBINED WITH THE DIGITAL TECHNOLOGY \\ IN THE TEACHING OF MATHEMATICS: A PANORAMA OF BRAZILIAN \\ RESEARCH
}

DOI: 10.23926/RPD.2526-2149.2020.v5.n3.p1593-1611.id905

\section{Francisco Ellivelton \\ Barbosa \\ Licenciado em Matemática \\ (IFCE)}

Mestrando do Programa de Pós-Graduação em Ensino de Ciências e Matemática do IFCE (PGECM/IFCE) ellivelton.barbosa@hotmail.c om

\section{Márcio Matoso de Pontes}

Graduado em Pedagogia (UFC)

Mestrando do Programa de Pós-Graduação em Ensino de Ciências e Matemática do IFCE (PGECM/IFCE) marciomatoso@hotmail.com

\section{Juscileide Braga de Castro \\ Doutora em Educação (UFC) \\ Professora da Faculdade de \\ Educação da UFC \\ (FACED/UFC) \\ Professora do Programa de Pós-Graduação em Ensino de \\ Ciências e Matemática do \\ IFCE (PGECM/IFCE) \\ juscileide@virtual.ufc.br}

Resumo: A gamificação tem ganhado espaço no ambiente escolar. Considerando esta realidade, tem-se como objetivo identificar evidências da eficácia da gamificação no contexto do ensino de matemática com o uso de tecnologias. Para isso, realizou-se uma Revisão Sistemática de Literatura, dos últimos dez anos, proveniente de estudos desenvolvidos no Brasil, publicados na plataforma Scielo, no portal de Periódicos da CAPES e em um conjunto de Periódicos que tinham como escopo o uso da tecnologia educacional. Os resultados mostram que a gamificação no ensino de matemática com as TDIC é utilizada a partir de jogos ou ambientes digitais com elementos de gamificação e ainda em atividades gamificadas. Os artigos avaliados destacam o engajamento como fator impulsionador do ensino de matemática quando atrelado a gamificação. As análises apontam que a gamificação possui a capacidade de contribuir para o engajamento devido a utilização dos diferentes elementos dos games. Palavras-chave: Revisão Sistemática. Gamificação. Tecnologias Digitais. Ensino de Matemática. TDIC.

\begin{abstract}
Gamification has gained ground in the school environment. Considering this reality, the objective of this paper is to identify if there is evidence of the effectiveness of gamification in the context of teaching mathematics with the use of technologies. To this end, a Systematic Literature Review of the last ten years was carried out, based on studies developed in Brazil, published on the Scielo platform, on the CAPES Journals portal and on a set of Journals whose scope was the use of educational technology. The results show that gamification in the teaching of mathematics with TDIC is used from games or digital environments with elements of gamification and even in gamified activities. The evaluated articles highlight engagement as a driving factor in the teaching of mathematics when linked to gamification. The analyzes show that gamification has the ability to contribute to engagement due to the use of different elements of games.
\end{abstract}

Keywords: Systematic Review. Gamification. Digital Technologies. Mathematics Teaching. TDIC. 


\section{INTRODUÇÃO}

A Matemática está presente nas mais diferentes atividades cotidianas, apesar disso, há diferenças significativas entre a Matemática usada no dia a dia e a Matemática utilizada em ambiente escolar. Este distanciamento entre os conteúdos e a realidade, maximiza o conhecimento abstrato, muitas vezes desprovido de representações concretas, fazendo prevalecer a memorização para o cumprimento de tarefas (SOARES; RÊGO, 2015). Em muitos casos, é dada ênfase em regras, em procedimentos e em modelos prontos, o que não contribui para a compreensão de conceitos matemáticos (CASTRO, 2016).

Considerando o cenário brasileiro, resultados de avaliações externas como do Sistema de Avaliação da Educação Básica (SAEB) apontam que estudantes da Educação Básica, em todos os níveis de ensino, possuem dificuldades com a Matemática (BRASIL, 2017a).

Além das diversas dificuldades, indagações na área de Ensino de Matemática apontam que a falta de estímulo para o aprendizado tornou-se um dos fatores de maior impacto enfrentados pelos docentes em sala, o que torna o ensino inviável e, consequentemente, o aprendizado da Matemática acaba por ser prejudicado (MOREIRA; KRAMER, 2007).

Um dos aspectos que têm contribuído para a desmotivação dos alunos em sala são as aulas mecanizadas, que acontecem de forma centrada no professor, com questões repetitivas embasadas no ato de decorar fórmulas pré-estabelecidas e resolução de exercícios. Entretanto, vale ressaltar que esse modelo mecanizado, nos dias de hoje, ainda é uma das referências educacionais mais predominantes nas salas de aulas do Brasil (SILVA, 2017).

Sobre o modelo mecanizado de ensino, Silva (2017) aponta que ele se mantém no contexto educacional, entretanto, a Educação passou por mudanças de comportamento bruscas, isso devido aos avanços das Tecnologias Digitais de Informação e Comunicação (TDIC).

$\mathrm{Na}$ sociedade atual, em meio às constantes transformações e inovações no ambiente escolar, é necessária uma melhor compreensão de como tais mudanças impactam a comunidade escolar como um todo. É importante notar que as crianças e os adolescentes estão imersos em uma coletividade virtual, cercados por smartphones, computadores, etc.

Assim, o avanço tecnológico veio de forma massiva, tomando espaço dentro da sala de aula como um recurso disponível para o ensino. Nessa perspectiva, ao se utilizar a tecnologia no ambiente escolar o professor se propõe a explorar as vantagens que este recurso pode trazer para a sala de aula, pois ao utilizá-la a seu favor, esta pode servir como uma forma de estimular o aluno ao aprendizado. Apesar de termos um avanço tecnológico, a Educação e a formação de 
professores no Brasil não segue o mesmo ritmo, dificultando sua ampla utilização em sala de aula.

Dentre as potencialidades que as TDIC podem oferecer, pode-se citar a exploração das múltiplas representações, como: imagens, tabelas, gráficos, dentre outros elementos da interface que podem potencializar a aprendizagem; as possibilidades de construção de gráficos com rapidez e agilidade; o acesso mais fácil à informação; assim como a viabilização da comunicação e da interação entre pessoas (CASTRO, 2016).

Castro (2016) explica que a depender da mediação, as tecnologias podem favorecer a construção de significados, possibilitando o engajamento dos estudantes. Ao trabalhar com situações reais e em contextos investigativos, por exemplo, pode-se "oportunizar a experimentação de ideias, o levantamento de hipóteses e a formulação de conjecturas" (CASTRO, 2016, p. 198).

Abordagens que favorecem a investigação, possibilitam que os estudantes sigam seu próprio ritmo, o que permite o desenvolvimento de diferentes habilidades e competências. Ressalta-se que na atualidade tem-se uma sociedade alicerçada pela vasta quantidade de recursos tecnológicos, globalização, rapidez e maior acessibilidade de informações. Este tipo de sociedade exige habilidades e competências dos cidadãos que a compõem e a escola ocupa um papel desafiador neste contexto social (COUTINHO; LISBÔA, 2011). Portanto, neste contexto de sociedade, o aluno é sujeito ativo no seu processo de aprendizagem, cabendo ao professor ser mediador do conhecimento.

As habilidades que podem ser desenvolvidas, dependerá da área de conhecimento e do ano escolar envolvido, de acordo com a Base Nacional Comum Curricular (BNCC). A BNCC ainda apresenta um conjunto de dez competências gerais que podem ser desenvolvidas nesse processo, como a de número 5: "Compreender, utilizar e criar tecnologias digitais de informação e comunicação de forma crítica, significativa, reflexiva e ética nas diversas práticas sociais (incluindo as escolares) para se comunicar, acessar e disseminar informações, produzir conhecimentos, resolver problemas e exercer protagonismo e autoria na vida pessoal e coletiva" (BRASIL, 2017b, p. 9).

A gamificação ${ }^{1}$ tem sido utilizada por alguns pesquisadores como Silva (2017), Andreetti, Egido e Santos (2017) no intuito de usar como uma estratégia para motivar e engajar os estudantes. Autores como Alves e Teixeira (2014) explicam que a gamificação está

\footnotetext{
${ }^{1}$ Este artigo considera que a gamificação é a utilização de mecânicas e dinâmicas de jogos para uso em outros contextos e atividades, para o engajamento de pessoas e a resolução de problemas.
} 
relacionada com a utilização da lógica e da mecânica dos games, em diferentes atividades, com ou sem tecnologias, o que pode gerar o engajamento por parte dos alunos.

Considerando o possível potencial das TDIC e da gamificação para o ensino de Matemática, têm-se as seguintes questões: Como a gamificação, aliada ao uso das TDIC, pode ser utilizada em sala de aula para o ensino de matemática? Como a gamificação com o uso das TDIC pode ajudar no engajamento nas aulas de matemática?

A partir destes questionamentos, procurou-se investigar sobre a utilização da gamificação aliada às TDIC no ambiente escolar. Diante de tais perguntas norteadoras, apontase como objetivo deste estudo, identificar se há evidências da eficácia da gamificação no contexto do ensino de matemática com o uso de TDIC. Este levantamento dar-se-á por meio de uma revisão sistemática de literatura.

Estruturalmente, este artigo está dividido em cinco seções. Após as considerações introdutórias, na segunda seção são abordados o conceito e a relevância da gamificação para o ensino, bem como aprofunda-se a discussão sobre gamificação, apresentando algumas de suas definições. Na terceira seção é descrito a metodologia abordada neste trabalho. Na quarta seção discutir-se-á os resultados e as discussões encontrados na pesquisa e, por fim, as considerações finais serão dispostas.

\section{A Utilização da Gamificação no CONTEXTo EduCaCional}

Pesquisas desenvolvidas nos últimos anos mostram que a gamificação em ambiente de ensino tem ganhado expressão, mas ainda é emergente e relativamente nova, o que corrobora para a gamificação como um método em crescimento (SILVA, 2017; MILANO et al., 2019; MOZER; NANTES, 2019; ANDREETTI; EGIDO; SANTOS, 2017; ROCHA; SOUZA, 2019).

Segundo Koch-Grünberg (2011, p. 20), o termo gamificação faz referência a determinado momento em que "pretende-se adotar elementos de jogos para uso em outros contextos e atividades que não são jogos puros e completos". No ambiente escolar, os objetos gamificados são ferramentas de ensino que se mostram com o auxílio das estruturas de jogos, por essa razão, possuem características específicas dos jogos (MOZER; NANTES, 2019).

Para a Educação atual, a ideia da gamificação é a de se fazer uso das características dos jogos, assim como as contribuições para interesse e para motivação dos discentes, se aproveitando da ludicidade existente neste método. Como Vianna et al. (2013, p. 108) abordam, "talvez seja a educação uma das áreas em que se tem maior expectativa com relação à extensão de benefícios passíveis de serem alcançados com a gamificação". Ao se fazer uso da 
gamificação como método de ensino, se supõe que ela possa refletir naturalmente na aprendizagem, pois esta torna viável a elaboração de ambientes que favorecem a motivação e a criatividade, surtindo efeito no ambiente educacional.

Viana et al.(2013) explicam que para a pessoa ativar a sua criatividade é necessário que o ambiente seja prazeroso, pois, dessa forma, haveria uma entrega pessoal ao que havia sido proposto, causando uma emoção agradável, tornando assim a motivação como uma fator necessário para o desenvolvimento de determinada atividade. Alves e Teixeira (2014, p. 140) indagam que a "gamificação pode explorar qualidades cognitivas, sociais, culturais e motivacionais" o que viabiliza a execução de atividades, além de se tornar um facilitador da aprendizagem.

Fardo (2013) fala da gamificação como sendo uma tendência educacional mediante a geração atual de discente no ambiente escolar, que já não mais exprimem uma correspondência com práticas educacionais fundamentalmente conteudistas, além da relação desta geração com a tecnologia.

Em sua essência, a gamificação é uma maneira de fazer uso das formas e raciocínios dos jogos para motivar, engajar e promover o aprendizado e, desta forma, a gamificação pode ser aplicada de duas maneiras: com ou sem o uso das Tecnologias Digitais; isso porque as mecânicas presentes nos jogos não são necessariamente dependentes de meios tecnológicos ou dispositivos digitais.

Para a efetiva utilização da gamificação no ambiente educacional, é necessário que os elementos de jogos, como a voluntariedade, os objetivos, as regras e os feedbacks estejam interconectados, possibilitando assim que o resultado final seja uma experiência que se aproxime da prática envolvida em um jogo real (FARDO, 2013). Além de que a voluntariedade de se jogar acarreta no uso das regras, obtenção de objetivos e retorno de feedbacks.

Fardo (2013) explica que a criação de um objetivo é o que impulsiona a participação em um jogo para se chegar ao resultado final. Os objetivos devem ser evidentes, se não o jogo se tornaria algo confuso e de difícil jogabilidade, causando assim a derrota do participante. Se o objetivo for complexo é necessário que este seja subdividido, possibilitando que ao se ultrapassar desafios menores o jogador seja capaz de alcançar o grande objetivo.

As regras seriam as delimitações pertencentes ao jogo, o que proporciona a concretização do ato de jogar. Elas determinam o início e o final do jogo, que pode variar de quantidade. As regras ainda auxiliam na organização de façanhas que o jogador deve fazer para 
a superação dos obstáculos impostos, além de possibilitar o desenvolvimento do pensamento estratégico do competidor (FARDO, 2013).

De acordo com Fardo (2013), para que a gamificação em sala supra o efeito esperado é necessário se utilizar dos feedbacks, que devem ser claros e diretos, eles são basicamente as informações do jogador sobre como funciona a sua ligação com os mais diversos aspectos que compõem a performance no game. Este é o ponto que a maioria dos jogos contam, com atualizações constantes de como os objetivos do jogo estão sendo atingidos.

A partir desses elementos expostos, é possível notar que a gamificação não se define apenas pela criação ou uso de jogos, mas assimila toda uma cultura que cria desafios que possibilitam o raciocinar, o integrar e o envolver do estudante, com o engajamento e motivação para o cumprimento dos objetivos.

Um ponto de importância que vale a pena evidenciar é a existência de barreiras a serem transpassadas para a implementação da gamificação em sala de aula de maneira efetiva. Dentre estas barreiras, pode-se citar a necessidade da formação para o uso efetivo em sala de aula, além do despreparo dos professores para a implementação de atividades que trabalham com auxílio de TDIC. Ainda que a gamificação venha se apresentando como um método promissor para o engajamento do aluno, uma das dificuldades para a elaboração de ambientes gamificados é a necessidade de estímulos que favoreçam a aprendizagem do aluno, o que necessita de um planejamento de qualidade e preparação de modo prático e teórico (TODA; SILVA; ISOTANI, 2017). A seguir, apresentar-se-á os procedimentos metodológicos da investigação.

\section{Procedimentos Metodológicos da Investigação}

Esta pesquisa foi realizada a partir de uma Revisão Sistemática de Literatura (RSL), a fim de investigar as produções científicas sobre o uso das TDIC e da gamificação como metodologia de ensino nas aulas de Matemática.

De acordo com Sampaio e Mancini (2007), a RSL é classificada como um estudo de natureza observacional ou experimental, pois foca na análise crítica da literatura. Nela, objetivase levantar métodos sistemáticos e explícitos para recuperar, para selecionar e para avaliar os resultados de trabalhos publicados na área de estudo. As etapas dessa pesquisa foram organizadas, respectivamente, segundo os passos sugeridos por Sampaio e Mancini (2007), a saber: [1] definição da pergunta de pesquisa, [2] busca de evidências que comprovam ou não a questão de pesquisa e [3] revisão e seleção dos estudos a serem analisados e [4] análise dos estudos. 
Na primeira fase, as perguntas definidas foram na busca por trabalhos que abordassem: 1) Como a gamificação, aliada ao uso das TDIC, pode ser utilizada em sala de aula para o ensino de matemática? 2) Como a gamificação com o uso das TDIC pode ajudar no engajamento nas aulas de matemática?

Como forma de responder aos questionamentos apresentados, iniciou-se a segunda fase da pesquisa. Para isso, foi feita pesquisa de artigos científicos publicados de 2010 a 2019, ou seja, dos últimos dez anos, provenientes de estudos desenvolvidos no Brasil, portanto, escritos em língua portuguesa e que foram publicados na plataforma Scielo, no portal de Periódicos da CAPES e em um conjunto de Periódicos que tinham como escopo o uso da tecnologia no ambiente educacional: [revista 1] Revista de Novas Tecnologias na Educação - RENOTE²; [revista 2], Revista Brasileira de Ensino de Ciências e Tecnologias - RBECT ${ }^{3}$; [revista 3], Revista Brasileira de Informática na Educação - RBIE*; [revista 4], Revista Tecnologias na Educação - TECEDU ${ }^{5}$; e [revista 5], Revista Prática docente - RDP.

A busca foi realizada por meio das palavras-chaves: Gamificação, Tecnologias Digitais e ensino de Matemática. Foram incluídos artigos publicados entre os anos de 2010 e 2019. As buscas foram realizadas dentre os meses de abril e agosto de 2020 e os critérios de eliminação e abrangimento foram definidos a partir de análise do título, do resumo, das palavras-chave e do texto de cada artigo.

A revisão e a seleção dos estudos deram início a terceira fase da pesquisa. Para isso, foram construídos quadros para que os dados fossem analisados mais criteriosamente na fase seguinte, tendo sido excluídos artigos que não estavam disponíveis para download. Os artigos analisados na pesquisa foram selecionados considerando a aderência e a pertinência ao tema por meio da leitura dos títulos e dos resumos.

$\mathrm{Na}$ quarta fase da pesquisa foi feita a avaliação crítica dos artigos, que consistiu na leitura do estudo para identificar aspectos relevantes que se repetiam ou se destacavam. Para uma melhor sistematização, foram construídos quadros para sintetizar os dados coletados com informações de cada pesquisa, contendo: ano de edição, volume, pesquisa sobre gamificação e pesquisa sobre gamificação, ensino de Matemática e TDIC, conforme será apresentado e

\footnotetext{
${ }^{2}$ Disponível em: https://seer.ufrgs.br/renote

${ }^{3}$ Disponível em: https://periodicos.utfpr.edu.br/rbect

${ }^{4}$ Disponível em: https://www.br-ie.org/pub/index.php/rbie/index

${ }^{5}$ Disponível em: https://tecedu.pro.br /

${ }^{6}$ Disponível em: http://periodicos.cfs.ifmt.edu.br/periodicos/index.php/rpd 
discutido nos resultados. A seguir, apresentar-se-á a discussão dos resultados desta revisão sistemática.

\section{Discussão dos RESUltados}

Os resultados preliminares obtidos nesta pesquisa podem ser vistos no Quadro 1, que mostra um resumo quantitativo dos artigos que envolvem Gamificação; Gamificação e Ensino de Matemática; e Gamificação, Ensino de Matemática e TDIC; dos últimos 10 anos.

Quadro 1 - Pesquisa dos últimos 10 anos

\begin{tabular}{|c|c|c|c|c|}
\hline Base de dados & $\begin{array}{c}\text { Total de artigos } \\
\text { analisados } \\
\mathbf{2 0 1 0 / 2 0 1 9}\end{array}$ & Gamificação & $\begin{array}{c}\text { Gamificação e } \\
\text { ensino de } \\
\text { matemática }\end{array}$ & $\begin{array}{c}\text { Gamificação, } \\
\text { ensino de } \\
\text { matemática e tdic }\end{array}$ \\
\hline RENOTE & 1201 & 25 & 1 & 0 \\
\hline RBECT & 431 & 2 & 1 & 1 \\
\hline RBIE & 278 & 5 & 1 & 1 \\
\hline TECEDU & 605 & 1 & 0 & 0 \\
\hline RPD & 132 & 10 & 0 & 0 \\
\hline SCIELO & 224633 & 133 & 5 & 4 \\
\hline Periódicos. & -7 & 197 & $\mathbf{9}$ & \\
\hline CAPES & - & 197 & 7 \\
\hline
\end{tabular}

Fonte: Elaboração dos autores

De acordo com o quadro 1 foram identificados nas bases de dados de periódicos, 2.647 trabalhos divididos nas revistas: RENOTE, RBECT, RBIE, TECEDU e RPD. Apesar da quantidade expressiva de artigos, apenas 54 envolviam gamificação, sendo que 4 trabalhavam gamificação e ensino de matemática e, deste total, 3 tratavam de gamificação, ensino de matemática e TDIC, dos autores: Toneis e Paulo (2019); Pinheiro, Seruffo e Pires (2019) e Castro et al.(2019).

A pesquisa também foi realizada nas bases de dados: da Scientific Electronic Library Online $(\mathrm{SciELO})^{8}$ e no Portal periódicos $\mathrm{CAPES}^{9}$, com as palavras chaves: Gamificação/ Ensino de Matemática/TDIC. Ainda que nos últimos 10 anos tenham sido publicados 224.633

\footnotetext{
${ }^{7}$ Não foi possível verificar o quantitativo de artigos disponíveis na base de dados de Periódicos CAPES no período que a pesquisa foi realizada.

${ }^{8}$ Disponível em: https://scielo.org/

${ }^{9}$ Disponível em: https://www.periodicos.capes.gov.br/ 
trabalhos na base de dados da Scielo, apenas 10 trabalhos mencionam ou trabalham com a gamificação, sendo que nenhum deles envolveu o ensino de Matemática, com ou sem TDIC.

Verifica-se ainda no quadro 1, que 133 artigos envolvendo gamificação foram encontrados na base dos Periódicos CAPES, destes, 5 envolviam ensino de Matemática e 4 envolviam ensino de Matemática e tecnologia. Os autores destes artigos são: Mozer e Nantes (2019); Freire e Carvalho (2019); Gomes e Silva (2018); Marinho et al. (2016) e Silva e Ferraz (2019).

A tendência de se trabalhar Matemática, no ambiente escolar, com o uso das TDIC pode ser constatada no total de artigos analisados. De um total de 9 artigos que mencionaram a gamificação aliada ao ensino de Matemática, 7 deles também exploraram as TDIC, o que corresponde a cerca de $77,78 \%$ dos artigos.

Ao analisar a frequência de publicações envolvendo gamificação nos últimos anos, verifica-se uma tendência de crescimento (Figura 1). Em especial, 2019 foi o ano em que mais ocorreu incidência de trabalhos que envolvem Matemática e as TDIC.

Figura 1 - Pesquisa envolvendo gamificação, ensino de matemática e TDIC nos últimos 10 anos

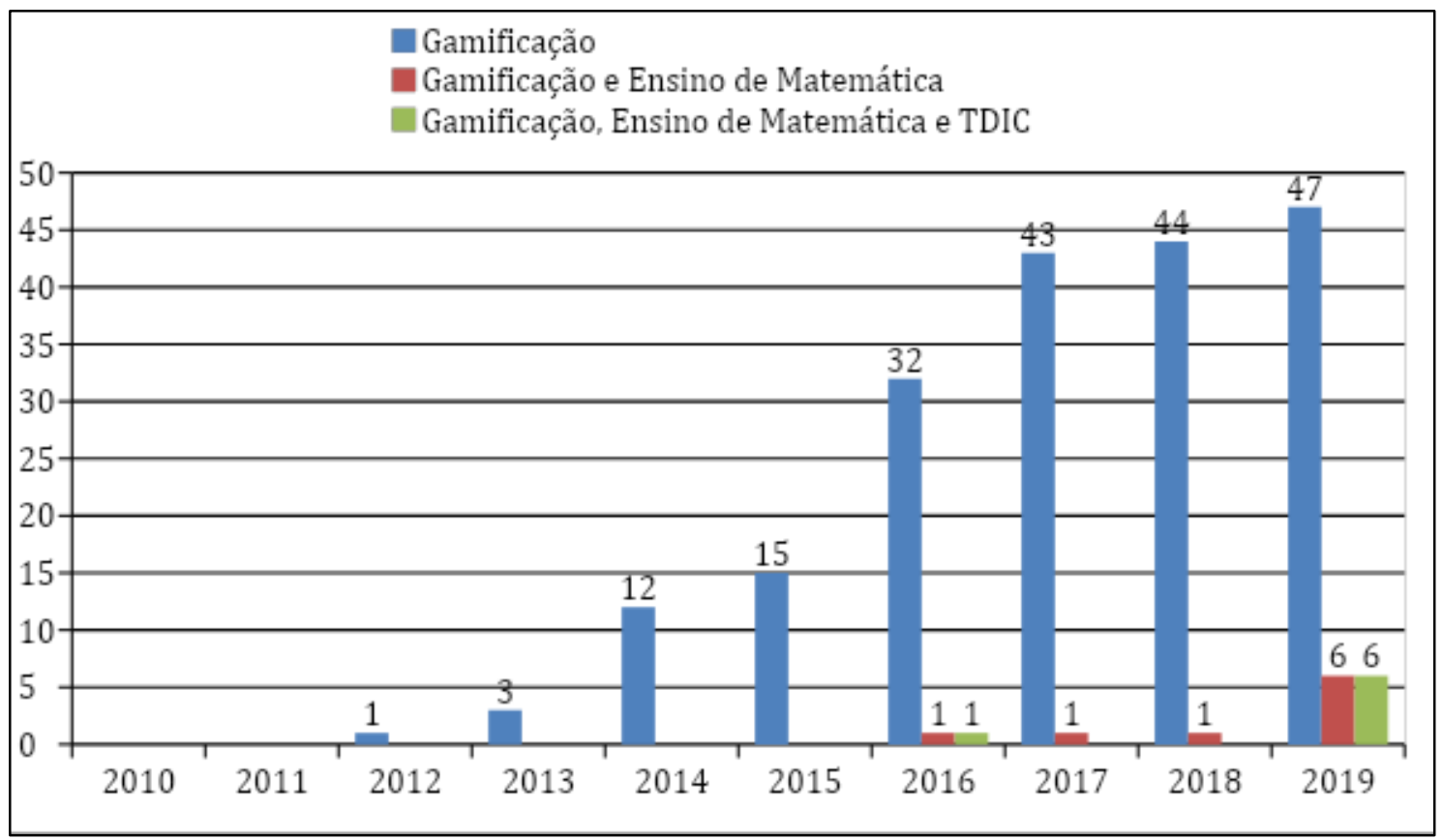

Fonte: Elaboração dos autores

A Figura 1 mostra 9 trabalhos que exploram a gamificação e o ensino de Matemática (legenda vermelha), no entanto, apenas 7 trabalhos que exploram a gamificação, o ensino de matemática e as TDIC (legenda verde), ou seja, apenas 3,55\% dos artigos que envolvem gamificação. 
Ainda que os trabalhos que relacionam gamificação e ensino de matemática, sem TDIC, não ajudem a responder as perguntas desta Revisão Sistemática, trazem evidências da utilização da gamificação no ensino de matemática. Por isso, estas pesquisas foram listadas no Quadro 2 e serão apresentadas na sequência.

Quadro 2 - Produções com gamificação no ensino de matemática sem TDIC

\begin{tabular}{|l|l|}
\hline \multicolumn{1}{|c|}{ Título da produção } & \multicolumn{1}{c|}{ Autores } \\
\hline $\begin{array}{l}\text { O uso de gamificação e dificuldades matemáticas: } \\
\text { possíveis aproximações. }\end{array}$ & $\begin{array}{l}\text { João Coelho Neto; } \\
\text { Marília Bazan Blanco; } \\
\text { Juliano Aléssio da Silva. }\end{array}$ \\
\hline $\begin{array}{l}\text { Gamificação: uma estratégia didática fundamentada } \\
\text { pela perspectiva da teoria das situações didáticas. }\end{array}$ & $\begin{array}{l}\text { Marcelo dos Santos Gomes; } \\
\text { Maria José Ferreira da Silva. }\end{array}$ \\
\hline
\end{tabular}

Fonte: Próprios autores.

A primeira pesquisa do Quadro 2 relaciona a gamificação como fator de aproximação nas dificuldades matemáticas. Coelho-Neto, Blanco e Silva (2017) trazem um levantamento de trabalhos que falam sobre a utilização da gamificação em instrumentos para alunos com dificuldades de aprendizagem em matemática e com discalculia. Este levantamento foi feito através de um Revisão Sistemática de Literatura, a partir de dois periódicos: Revista Brasileira de Informática na Educação e a Revista de Novas Tecnologias na Educação. Também foram analisadas as base de dados: Scielo Library, BIREME Biblioteca, Science Direct, ACM Library e IEEE Xplore Digital Library. No levantamento de Coelho-Neto, Blanco e Silva (2017) foram encontrados 3 artigos com gamificação e Matemática, mas nenhum artigo que envolvesse esse tema atrelado a discalculia.

Os autores apontam sobre a relevância do uso de instrumento no processo de ensino e de aprendizagem, assim como usar a gamificação de modo a facilitar o ensino de pessoas com necessidades intelectuais específicas. Ao término do levantamento fica evidente a falta de trabalhos que tratam da gamificação no ensino de matemática e a falta, mais evidente da gamificação no ensino de matemática voltada para alunos com discalculia. Deste ponto, os autores ressaltam a importância de pesquisas que visem esta temática.

Gomes e Silva (2018) apontam para a gamificação como um possível método da implementação das estratégias didáticas para o ensino de matemática. Para isto, os autores buscaram validar sua pesquisa fundamentada na Teoria das Situações Didáticas quando usada no ensino de um objetivo didático definido. Os autores explicam que a gamificação não envolve apenas o uso de jogos em sala de aula, mas trata-se da implementação dos elementos dos jogos em determinado objetivo didático. 
De uma forma geral, observa-se que a procura por meios de se fazer uso da gamificação sem a utilização das tecnologias, ainda se limita a poucas pesquisas do gênero, isso pode ocorrer devido a dificuldade de tornar uma atividade comum do cotidiano do aluno, como um livro didático, em uma atividade gamificada, mas ainda assim é possível o uso de elementos dos jogos nas mais diversas aplicações diárias da sala de aula.

Dentre estas aplicações em sala de aula têm-se o uso da gamificação para o ensino de matemática com TDIC (Figura 1). Tavares e Gottschalck (2019) indicam que ao trabalhar a gamificação aliada a tecnologia se abre espaço para um ensino interativo e motivador. Nesta perspectiva, no Quadro 3, estão apresentadas as produções que apontam a TDIC atrelada a gamificação no ensino de matemática.

Quadro 3 - Produções com gamificação para o ensino de matemática com auxílio das TDIC

\begin{tabular}{|c|c|}
\hline Título da produção & Autores \\
\hline $\begin{array}{l}\text { O game DragonBox } 12+\text { e o papel das metáforas em } \\
\text { sala de aula para o ensino da álgebra escolar. }\end{array}$ & $\begin{array}{l}\text { Cristiano Natal Toneis; } \\
\text { Rosa Monteiro Paulo. }\end{array}$ \\
\hline $\begin{array}{l}\text { Experiência de Uso de um Aplicativo Educacional } \\
\text { Para Dispositivos Móveis no Município de Castanhal } \\
\text { - Pará: Experience of Using an Educational } \\
\text { Application for Mobile Devices in the Municipality } \\
\text { of Castanhal. }\end{array}$ & $\begin{array}{l}\text { Paulo Sérgio Brito Pinheiro; } \\
\text { Marcos César da Rocha Seruffo; } \\
\text { Yomara Pinheiro Pires. }\end{array}$ \\
\hline $\begin{array}{l}\text { Gamificação no Ensino de Matemática: das diretrizes } \\
\text { curriculares do paraná à sala de aula, via plano de } \\
\text { trabalho docente. }\end{array}$ & $\begin{array}{l}\text { Merris Mozer; } \\
\text { Eliza Adriana Sheuer Nantes. }\end{array}$ \\
\hline $\begin{array}{l}\text { Classcraft: a Aprendizagem que se Transforma num } \\
\text { Desafio Permanente! }\end{array}$ & $\begin{array}{l}\text { Dora Sofia da Cunha Freire; } \\
\text { Ana Amélia Amorim Carvalho. }\end{array}$ \\
\hline $\begin{array}{l}\text { Aplicação móvel de matemática no ensino básico } \\
\text { para crianças do ensino fundamental I do } 1^{\circ} \text { ao } 3^{\circ} \\
\text { ano. }\end{array}$ & $\begin{array}{l}\text { Aldenia da Silva Marinho; } \\
\text { Alexander Von Cernik Melo; } \\
\text { Gianpierre Herrera Poggi; } \\
\text { Marianne Bállico Kosiur; } \\
\text { Wagner Rosa Marrane; } \\
\text { Cláudio Boghi. }\end{array}$ \\
\hline $\begin{array}{l}\text { A Visão do Professor sobre Jogos Digitais no Ensino } \\
\text { da Matemática para alunos com Deficiência } \\
\text { Intelectual: estado da arte. }\end{array}$ & $\begin{array}{l}\text { Simone dos Santos Venturelli Antunes Silva; } \\
\text { Denise Pereira de Alcantara Ferraz. }\end{array}$ \\
\hline $\begin{array}{l}\text { A gamificação como estratégia para explorar a } \\
\text { interpretação de dados estatísticos a } \\
\text { partir de um Recurso Educacional Digital }\end{array}$ & $\begin{array}{l}\text { Juscileide Braga de Castro } \\
\text { Maria de Fátima Souza } \\
\text { Márcia Duarte Medeiros } \\
\text { Joyce da Silva Sousa } \\
\text { Lídya de Lima Monteiro } \\
\text { José Aires de Castro Filho }\end{array}$ \\
\hline
\end{tabular}


A análise dos 7 trabalhos que envolvem gamificação, ensino de matemática e TDIC buscou responder as perguntas: 1) Como a gamificação, aliada ao das TDIC, pode ser utilizada em sala de aula para o ensino de matemática? 2) Como a gamificação com o uso das TDIC pode ajudar no engajamento nas aulas de matemática? Na busca de responder a estas questões, apresentar-se-á as discussões em subseções a seguir.

\subsection{O USO DA GAMIFICAÇÃO NO ENSINO DE MATEMÁTICA COM TDIC}

Os artigos analisados mostram o uso da gamificação em, pelo menos, dois contextos distintos no ensino de matemática: [1] a partir do uso de jogos ou ambientes digitais com elementos de gamificação (CASTRO et al, 2019; TONEIS; PAULO, 2019; MARINHO et al, 2016; MOZER; NANTES, 2019; PINHEIRO; SERUFFO; PIRES, 2019) e [2] em atividades gamificadas com o uso das TDIC (FREIRE; CARVALHO, 2019; MOZER; NANTES, 2019; SILVA; FERRAZ, 2019).

Castro et al (2019) consideraram os elementos de gamificação para a elaboração do Recurso Educacional Digital Divertix ${ }^{10}$ que explora a interpretação de gráficos estatísticos. Dentre os elementos de gamificação usados pelos autores, pode-se destacar a narrativa, usada para inserir o jogador na rotina de produção de uma revista digital e na resolução de um mistério que solicita a utilização de habilidades Estatísticas. O jogo digital desenvolvido por Castro et al (2019) ainda utiliza feedbacks imediatos, sendo estes visuais e textuais; sistemas de recompensas à medida que o jogador avança de nível; e temporização decrescente. De acordo com os autores, estes elementos devem ajudar no engajamento dos estudantes, potencializando o desenvolvimento de habilidades da Estatística, contudo, ainda precisa ser validado no contexto da escola.

Toneis e Paulo (2019) trazem em seu artigo um mapeamento sobre o game DragonBox Algebra $12+{ }^{11}$ salientando as possibilidades para o ensino da álgebra escolar. Os autores mostram as relações entre as metáforas do game e os significados algébricos na matemática escolar, indicando possibilidades de adequação das metáforas com os conhecimentos algébricos, tornando assim a álgebra componente integrante das regras do game. Para tal, a intervenção do professor na realização da atividade digital se deu de forma imprescindível, para que as situações matemáticas apresentadas no jogo pudessem ser compreendidas pelos alunos e ser feita a relação com o objetivo em sala.

\footnotetext{
${ }^{10}$ Disponível em: https://plataformaintegrada.mec.gov.br/recurso?id=36040\&name=Divertix

11 Disponível em: https://dragonbox.com/products/algebra-12
} 
Toneis e Paulo (2019) denotam que a álgebra nos livros didáticos se apresenta apenas com definições, conceitos ou regras algébricas generalizadas, e após isto, realizam os problemas na forma de exemplos, diferente de como isto pode se apresentar em um game que é mais centrado no jogador e no seu progresso. No game, o jogador tem o seu próprio tempo para realizar os problemas e pode recomeçar sempre que preciso for, sem a aflição de estar trabalhando em um exercício de matemática.

De forma geral, observa-se que as regras do jogo e os objetivos ampliam a visão do estudante, ao querer transpor os desafios impostos na forma de metáforas, sendo necessário a inter-relação do que é visto no jogo com o que é vivenciado na sala de aula.

Pinheiro, Seruffo e Pires (2019) fazem um estudo de caso relacionando a criação de aplicações gamificadas para o ensino de matemática, com o intuito de constatar a influência que a gamificação pode ter sobre o ensino de matemática. Para os autores, a aplicação móvel com elementos típicos dos jogos, como recompensas, progressão e competição, gerou uma motivação ao estudo de conteúdos trabalhados em sala, gerando o ensino mais interessante.

A pesquisa feita por Marinho et al. (2016) foi direcionada a explorar assuntos como as quatro operações básicas da matemática, por meio de aplicativo que continha animações e elementos gamificados. O aplicativo móvel desenvolvido por Marinho et al (2016) ainda utiliza desafios matemáticos, feedbacks; e sistemas de recompensas desbloqueando novos níveis, a depender do avanço do aluno no game. Para os autores, estes elementos devem fomentar um aprofundamento matemático e específico dos conteúdos em sala, necessários para o avanço do game, tornando o aprendizado mais eficaz, devido ao interesse do estudante.

Mozer e Nantes (2019) expressam como é possível a utilização simples da gamificação, na forma de jogo ou atividade gamificada. Os autores mostram que mesmo com poucos recursos educacionais é possível incentivar os participantes a interagirem . Além disso, a pesquisa aponta para como o aprendizado matemático é difícil, mas essencial, podendo a gamificação propiciar um aprendizado mais prazeroso e dinâmico da matemática.

Freire e Carvalho (2019) trazem a visão do uso da tecnologia aplicada com o auxílio da gamificação com a plataforma Classcraft. Os pesquisadores utilizaram uma atividade gamificada para o ensino de conceitos e elementos matemáticos, realizando uma análise das mudanças de comportamentos dos estudantes ao participarem de atividades gamificadas.

Para verificar as contribuições da gamificação, Freire e Carvalho (2019) realizaram pesquisa de intervenção, dividindo os sujeitos em grupo controle e experimental. O grupo experimental vivenciou atividades gamificadas, com o auxílio da plataforma Classcraft, 
enquanto que no grupo controle estas mesmas atividades foram realizadas sem o uso da gamificação. Ao fim da pesquisa foi evidenciado o avanço do grupo experimental com relação a turma controle. Contudo, os autores ressaltam, que não foi apenas o uso da tecnologia que fez o grupo experimental evoluir, mas sim o uso de gamificação que promovia a competição da turma e o envolvimento dos alunos.

Silva e Ferraz (2019) explicitam a partir de uma Revisão Sistemática da Literatura como os professores estão despreparados para o uso das TDIC, dos jogos digitais ou ainda de elementos gamificados. $\mathrm{O}$ trabalho dos autores traz reflexões de como a falta de qualificação pode ser um empecilho para o uso efetivo de recursos e metodologias diferenciadas. Isso inclui a adequação de jogos para conteúdo específico de matemática, precisando uma reformulação das formações iniciais e continuadas para o uso de tecnologias e jogos digitais.

$\mathrm{Na}$ análise feita nos trabalhos, se identifica como que a utilização da gamificação em sala de aula pode auxiliar no ensino de conteúdos matemáticos, apesar de não atingir o efeito desejado em todos os estudantes. Os resultados apontam que com a gamificação aliada ao uso das TDIC se torna possível um aprendizado de forma coletiva e fluida, apesar de ser um método que baseia-se em estímulos e recompensas. As produções investigadas indicam que o trabalho com gamificação pode oportunizar a criação de diferentes estratégias podendo assim melhorar o processo de aprendizado matemático. As pesquisas apontam para resultados positivos que o ato de ensinar com a gamificação pode gerar, como a motivação para a aprendizagem e facilidade de interpretação de determinados conteúdos, conforme se verifica na próxima seção.

\subsection{O ENGajamento PROPORCIONAdo PELA GAMIFICAÇÃo NO ENSINO DE MATEMÁTICA COM TDIC}

Considerando o cenário educacional atual, a gamificação tem sido utilizada para proporcionar o envolvimento, engajamento e a motivação dos estudantes (CASTRO et al, 2019). Todos os artigos avaliados destacam o engajamento como fator impulsionador do ensino de matemática quando atrelado a gamificação.

O trabalho de Freire e Carvalho (2019) traz a visão do uso da tecnologia aplicada com o auxílio da gamificação, com o uso da plataforma Classcraft ${ }^{12}$. Os autores apontam os pontos que a gamificação ofertada pela plataforma pode tornar a atividade mais interativa e

\footnotetext{
${ }^{12}$ Disponível em: https://www.classcraft.com/pt/ . Classscraft é uma plataforma online que se apresenta de forma similar a um jogo. Por se tratar de uma plataforma online ela sempre se encontra disponível para acesso nos mais diversos dispositivos.
} 
motivadora, como: pontuação, criação de quizzes $^{13}$, personalização de avatar, estímulo da competição, criação de equipes, entre outros pontos que podem auxiliar no engajamento pela atividade desenvolvida.

Castro et al. (2019) apresentam o tempo limite ou a utilização de um temporizador, como fator impulsionador à motivação dos alunos ao ato de aprender vinculado à gamificação. Os autores ainda destacam o sistema de recompensas e de níveis como elementos que podem ajudar no envolvimento dos estudantes.

Pinheiro, Seruffo e Pires (2019) explanam sobre como o simples uso da tecnologia não é fator único de sucesso ou de fracasso de determinada atividade. É necessário que esta ferramenta esteja integrada a outros processos. A gamificação foi um dos pilares que constituíram a produção do aplicativo usado na pesquisa, devido a sua possibilidade de promover envolvimento e engajamento. Os autores apontam para esse engajamento ligado diretamente ao uso de um jogo de celular com elementos da gamificação para o ensino de conteúdos matemáticos.

Ainda que seja uma pesquisa aplicada em públicos diferentes, o estudo de Marinho et al. (2016) tem relação com a de Mozer e Nantes (2019) pois expressa como é possível a utilização simples da gamificação, com poucos recursos educacionais, mas que incentiva os participantes a interação mais espontânea. Ressalta-se ainda a contribuição para professores, orientando como o uso do método da gamificação pode favorecer o ensino e aprendizagem da matemática.

Mozer e Nantes (2019) pontuam que o engajamento, ao se trabalhar o ensino de matemática com elementos gamificados, se dá por estabelecer desafios a serem transpassados, além da atribuição de pontos para cada acerto, o que estimula a competitividade dos alunos, tornando o ato de ultrapassar as pontuações dos colegas um fator de estímulo. Diferente de Mozer e Nantes (2019), Marinho et al. (2016) atribuem a motivação dos estudantes aos elementos utilizados, as mecânicas dos jogos e as dinâmicas da atividade gamificada, o que acarreta no engajamento e no direcionamento do comportamento dos jogadores/alunos.

O trabalho de Silva e Ferraz (2019), no que lhe concerne, explicam que a utilização de jogos digitais em sala, de aula motivam o aprendizado. Os trabalhos avaliados por Silva e Ferraz (2019) apontam que a motivação dos estudantes, em grande parte, acontece porque a aula com TDIC foge das atividades cotidianas e possibilitam aos alunos o desenvolvimento, a partir desta

\footnotetext{
${ }^{13}$ Quizzes são questionários de perguntas e respostas que se apresentam na forma de jogo. Eles possuem o objetivo de avaliar os conhecimentos adquiridos sobre determinado assunto.
} 
interação, de outras habilidades. Por sua vez, o trabalho de Toneis e Paulo (2019) traz a visão de que o ato de jogar motiva o aluno/jogador a prosseguir apesar dos desafios, dando uma noção de liberdade e interatividade.

$\mathrm{Na}$ análise dos trabalhos arrazoados, pôde se identificar o engajamento como fator de importância ao ato de se trabalhar com a TDIC no ensino com jogos e elementos gamificados. As produções ainda mostram como o formato da atividade desempenhada, a utilização de recursos tecnológicos e os desafios impostos podem atuar como elemento de engajamento para os alunos. Esse incentivo ao aprendizado, gerado em decorrência do uso da gamificação em sala, surge a partir de diferentes fatores, como: elementos e mecânicas de game, o que envolve sistema de recompensa, níveis, temporizador, narrativa, dentre outros elementos. Esta realidade auxilia no engajamento da matemática, disciplina esta que trabalha com diversos conceitos abstratos.

Destarte, na presente seção foram expostos os levantamentos feitos nesta RSL acerca da utilização da gamificação no ensino. Na seção a seguir, apresentar-se-á as considerações finais acerca desta pesquisa.

\section{CONSIDERAÇÕES FINAIS}

Este trabalho se propôs a apresentar um levantamento de produções que evidenciam a utilização da gamificação na disciplina de matemática como auxílio ao ato de ensinar. Para isso, considerou o panorama de pesquisas brasileiras e partiu das seguintes perguntas norteadoras: “Como a gamificação, aliada ao uso das TDIC, pode ser utilizada em sala de aula para o ensino de matemática? Como a gamificação, com o uso das TDIC, pode ajudar no engajamento nas aulas de matemática?".

Ao analisar as formas de utilização da gamificação no ensino de matemática, com o uso das TDIC, verificou-se contextos de uso e de produção de jogos ou de ambientes digitais com o uso de elementos de gamificação; e ainda, atividades gamificadas com o uso de TDIC, ou seja, considerando a gamificação como uma abordagem metodológica. Vale destacar a baixa incidência de trabalhos encontrados nos últimos 10 anos, que envolvem gamificação, ensino de matemática e TDIC.

A gamificação possui a capacidade de contribuir para o ensino de matemática devido a utilização dos diferentes elementos dos games, como: a criação de objetivos, a utilização de regras específicas, o uso de feedbacks, a escala de pontos, o ranking; além do estímulo competitivo entre os alunos, o que acarreta como fator motivador ao aprendizado matemático. 
Percebe-se que as produções surgem da necessidade de meios que favoreçam o ato de ensinar e de se aprender matemática de forma satisfatória, com experiências motivadoras e entusiasmantes.

Na pesquisa realizada foi evidenciado, através de observações e levantamentos, como que o uso de atividades gamificadas e jogos digitais podem potencializar o ensino de matemática, contextualizando o que é visto na atividade com o que é trabalhado em sala, além de fornecer um auxílio na aprendizagem do aluno.

Decerto, acredita-se que este estudo possa contribuir como material substancial de pesquisa para a área da gamificação aplicada ao ensino de matemática, já que a quantidade de pesquisas desenvolvidas nesta área de pesquisa ainda é muito limitada, principalmente quando se trabalha na gamificação como método de ensino.

\section{REFERÊNCIAS}

ALVES, Marcia Maria; TEIXEIRA, Oscar. Gamificação e objetos de aprendizagem: contribuições da gamificação para o design de objetos de aprendizagem. FADEL, LM, et al. Gamificação na Educação. São Paulo: Pimenta Cultural, p. 122-142, 2014.

ANDREETTI, Thais Cristine; EGIDO, Sidnéia Valero; SANTOS, Luciane Mulazani dos. A gamificação no âmbito da Educação Matemática. Colóquio Luso-Brasileiro de EducaçãoCOLBEDUCA, v. 2, 2017.

BRASIL. Ministério da Educação. SAEB 2017. Brasília: INEP, 2017a.

BRASIL. Ministério da Educação. Secretaria da Educação Básica. Base nacional comum curricular. Brasília, DF, 2017b. Disponível em:

http://basenacionalcomum.mec.gov.br/images/BNCC_EI_EF_110518_versaofinal_site.pdf. Acesso em 25 out. 2020.

CASTRO, Juscileide Braga de. Construção do conceito de covariação por estudantes do ensino fundamental em ambientes de múltiplas representações com suporte das tecnologias digitais. 2016. 275f. - Tese (Doutorado) - Universidade Federal do Ceará, Programa de Pós-graduação em Educação Brasileira, Fortaleza (CE), 2016.

CASTRO, Juscileide Braga de; SOUZA, Maria de Fátima; MEDEIROS, Márcia Duarte; SOUSA, Joyce da Silva; MONTEIRO, Lídya de Lima; CASTRO FILHO, José Aires de. A gamificação como estratégia para explorar a interpretação de dados estatísticos a partir de um Recurso Educacional Digital. Revista Tecnologias na Educação - TECEDU, [S.L.], v. 31, a. 11, p. 1-19, dez. 2019. Edição Temática XII-IV Congresso sobre Tecnologias na Educação Ctrl+e, 2019.

COELHO NETO, João; BLANCO, Marília Bazan; SILVA, Juliano Aléssio da. O uso de gamificação e dificuldades matemáticas: possíveis aproximações. Revista Novas Tecnologias na Educação, [Rio Grande do Sul], v. 15, n. 1, p. 1 - 9, 2017. 
COUTINHO, Clara; LISBÔA, Eliana. Sociedade da informação, do conhecimento e da aprendizagem: desafios para a educação no século XXI. Revista de Educação. v. XVIII, n. 1, p. 5-22. 2011.

FARDO, Marcelo Luis. A gamificação como estratégia pedagógica: estudo de elementos dos games aplicados em processos de ensino e aprendizagem. 2013. 106 f. Dissertação (Mestrado) - Curso de Programa de Pós-graduação em Educação, Universidade de Caxias do Sul, Caxias do Sul, 2013.

FREIRE, Dora Sofia da Cunha; CARVALHO, Ana Amélia Amorim. Classcraft: a aprendizagem que se transforma num desafio permanente! Revista Intersaberes, [s. L.], v. 14, n. 31, p. 58-74, mar. 2019.

GOMES, Marcelo dos Santos; SILVA, Maria José Ferreira da. Gamificação: uma estratégia didática fundamentada pela perspectiva da teoria das situações didáticas. Horizontes -

Revista de Educação, [s. L.], v. 6, n. 11, p. 18-30, jun. 2018.

KOCH-GRÜNBERG, Tim Theodor. Gameful Connectivism: social bookmarking no SAPO Campus. 2011. 130 f. Dissertação (Mestrado) - Curso de Mestrado em Comunicação Multimédia, Departamento de Comunicação e Arte, Universidade de Aveiro, Portugal, 2011.

MARINHO, Aldenia da Silva; MELO, Alexander Von Cernik; POGGI, Gianpierre Herrera; KOSIU, Marianne Bállico; MARRANE, Wagner Rosa; BOGHI, Cláudio. Aplicação móvel de matemática no ensino básico para crianças do ensino fundamental I do $1^{\circ}$ ao $3^{\circ}$ ano.

Research, Society And Development, [S. L.], v. 3, n. 1, p. 69-90, set. 2016.

MILANO, Thomas Bersagui; SILVA, Mirian Linhares Siqueira da; AZEVEDO, Fernanda Chites; OGLIARI, Lucas Nunes. O jogo digital como proposta de gamificação no ensino de história da matemática. Boletim Cearense de Educação e História da Matemática, v. 6, n. 17, p. 20-33, 2019.

MOREIRA, Antonio Flavio Barbosa; KRAMER, Sonia. Contemporaneidade, educação e tecnologia. Educ. Soc., Campinas , v. 28, n. 100, p. 1037-1057, out. 2007 . Disponível em http://www.scielo.br/scielo.php?script=sci_arttext\&pid=S0101-73302007000300019. Acesso em 22 de maio de 2020. DOI: 10.1590/S0101-73302007000300019.

MOZER, Merris; NANTES, Eliza Adriana Sheuer. Gamificação no Ensino de Matemática: das diretrizes curriculares do paraná à sala de aula, via plano de trabalho docente. Research, Society And Development, [s.1.], v. 8, n. 4, p. 1-30, 25 fev. 2019.

PINHEIRO, Paulo Sérgio Brito; SERUFFO, Marcos César Da Rocha; PIRES, Yomara Pinheiro. Experiência de Uso de um Aplicativo Educacional Para Dispositivos Móveis no Município de Castanhal - Pará: Experience of Using an Educational Application for Mobile Devices in the Municipality of Castanhal. Revista Brasileira de Informática na Educação RBIE, [s. 1.], v. 27, n. 3, p. 242 - 264, 2019.

ROCHA, Paul Symon Ribeiro; SOUZA, Cintia Soares Januário de. Influência da Gamificação no Processo de Ensino-Aprendizagem em uma Turma do $9^{\circ}$ ano do Ensino Fundamental. In: Anais da VII Escola Regional de Computação do Ceará, Maranhão e Piauí. SBC, 2019. p. 103-110. 
SAMPAIO, Rosana Ferreira; MANCINI, Marisa Cotta. Estudos de Revisão Sistemática: um guia para síntese criteriosa da evidência científica. Revista Brasileira de Fisioterapia, São Carlos, v. 11, n. 1, p. 83-89, jan/fev. 2007.

SILVA, João Batista da. O contributo das tecnologias digitais para o ensino híbrido: o rompimento das fronteiras espaço-temporais historicamente estabelecidas e suas implicações no ensino. ARTEFACTUM-Revista de estudos em Linguagens e Tecnologia, v. 15, n. 2, 2017.

SILVA, Simone dos Santos Venturelli Antunes; FERRAZ, Denise Pereira de Alcantara. A Visão do Professor sobre Jogos Digitais no Ensino da Matemática para alunos com Deficiência Intelectual: estado da arte. Educação Matemática Pesquisa: Revista do Programa de Estudos Pós-Graduados em Educação Matemática, [s.1.], v. 21, n. 1, p. 180-196, 29 abr. 2019.

SOARES, Luís Havelange; RÊGO, Rogéria Gaudêncio do. O Concreto e o Abstrato no Ensino de Matemática In: Anais do $4^{\circ}$ Simpósio Internacional de Pesquisa em Educação Matemática.Ilhéus: UESC, 2015.

TAVARES, Daniela; GOTTSCHALCK, Diana Raquel Schneider. A gamificação como ferramenta no processo de ensino aprendizagem dos alunos no curso técnico na modalidade EAD. In: Anais V COLBEDUCA - COLÓQUIO LUSO-BRASILEIRO DE EDUCAÇÃO, 2019, Joinville/sc. Joinville/sc: Periódicos Udesc, 2019.

TODA, Amando Maciel; SILVA, Alan Pedro da; ISOTANE, Seiji. Desafios para o Planejamento e Implantação da Gamificação no contexto Educacional. Revista Novas Tecnologias na Educação - RENOTE, [S.L.], v. 15,n.2, 01-10, dez. 2017. Universidade Federal do Rio Grande do Sul. http://dx.doi.org/10.22456/1679-1916.79263.

TONEIS, Cristiano Natal; PAULO, Rosa Monteiro. O game DragonBox 12+ e o papel das metáforas em sala de aula para o ensino da álgebra escolar. Revista Brasileira de Ensino de Ciência e Tecnologia, v. 12, n. 1, 2019. Disponível em:

https://periodicos.utfpr.edu.br/rbect/articl e/view/8006. Acesso em: 22 de maio de 2020.

VIANNA, Ysmar; VIANNA, Maurício; MEDINA Bruno; TANAKA Samara. E o futuro?. In: VIANNA, Ysmar; VIANNA, Maurício; MEDINA Bruno; TANAKA Samara. Gamification, Inc: como reinventar empresas a partir de jogos. Rio de Janeiro: MJV, 2013.

Recebido em: 27 de agosto de 2020. Aprovado em: 19 de novembro de 2020. 